\title{
Sleep-Disordered Breathing in Alcoholics
}

\author{
Michael S. Aldrich, Kirk J. Brower, and Janette M. Hall
}

\begin{abstract}
Sleep apnea and related disorders contribute to disturbed sleep in abstinent alcoholics. In an earlier report from our group, sleepdisordered breathing was common and increased with age in a cohort of 75 abstinent alcoholics. We now report an extension of the previous work that includes studies of an additional 103 abstinent alcoholics undergoing treatment for alcoholism (total sample $=188$ ) and a comparison group of $\mathbf{8 7}$ normal subjects. The presence and severity of sleep-disordered breathing was assessed with polysomnography. Among the alcoholics, sleep-disordered breathing (defined as $\mathbf{1 0}$ or more apneas plus hypopneas per hour of sleep) was present in $3 \%$ of 91 subjects under age $40,17 \%$ of 83 subjects age 40 to 59 , and $50 \%$ of 14 subjects age 60 or over. Subjects with sleepdisordered breathing were more likely to be male and had more severe sleep disruption and nocturnal hypoxemia and more complaints related to daytime sleepiness than subjects without sleepdisordered breathing. In a multiple linear regression analysis, age and body mass index were significant predictors of the presence of sleep-disordered breathing, whereas smoking history and duration of heavy drinking were not predictors after controlling for the effects of age and body mass index. Our findings suggest that sleepdisordered breathing contributes significantly to sleep disturbance in a substantial proportion of older alcoholics and that symptomatic sleep-disordered breathing increases with age in alcoholics. Sleepdisordered breathing, when combined with existing cardiovascular risk factors, may contribute to adverse health consequences in alcoholics.
\end{abstract}

Key Words: Alcoholism, Sleep, Sleep Disorders, Sleep-Disordered Breathing, Obstructive Sleep Apnea.

W HILE THE association of alcohol use with snoring is well known, snoring was generally considered clinically of no importance before the discovery of obstructive sleep apnea (OSA). With accumulating evidence that OSA has significant health consequences, the effects of alcohol on breathing assume added significance.

OSA is characterized by periods of airway narrowing or closure during sleep. During sleep, the upper airway dilator muscles that maintain airway patency become less active, the diameter of the airway decreases, and the resistance to breathing increases. The increased force generated by in-

From the University of Michigan Alcohol Research Center (M.S.A., K.J.B., J.M.H.), and the Departments of Neurology (M.S.A.) and Psychiatry (K.J.B., J.M.H.), University of Michigan Medical Center, and Ann Arbor VA Medical Center, Ann Arbor, Michigan.

Received for publication April 9, 1998; accepted October 3, 1998

This study was supported by Center Grant 5 PO50 AA07378 from the National Institute on Alcohol Abuse and Alcoholism.

Reprint requests: Michael S. Aldrich, M.D., Professor of Neurology, Director, Sleep Disorders Center, University of Michigan Medical Center, UH8D8820, Box 0117, 1500 East Medical Center Drive. Ann Arbor, MI 48109. 0117.

FAX: (734) 647-9065

E-mail: maldrich@umich.edu

Copyright (c) 1999 by The Research Society on Alcoholism. spiratory muscles to overcome the higher resistance can lead to collapse of the pharyngeal airway. Once the airway closes, a partial awakening is usually required to activate the upper airway dilator muscles and reopen the airway. The repeated arousals and awakenings lead to sleep disruption and daytime sleepiness. With severe OSA, apneas followed by arousals occur virtually every minute of the night.

Alcohol relaxes upper airway dilator muscles, which leads to upper airway narrowing, increased resistance to breathing, increased airflow velocity, and increased snoring. Evening alcohol consumption causes increased airway resistance during wakefulness and during the first $2 \mathrm{hr}$ of sleep, when the blood alcohol concentration is high. ${ }^{1-3}$ The increased airway resistance and associated increased inspiratory effort may lead to airway occlusion in persons who do not usually have obstructive apneas. Persons who snore are more likely to develop obstructive apneas after alcohol consumption, because their pharyngeal airways tend to be smaller than those of nonsnorers. Similarly, men, who tend to have narrower pharyngeal airways than women, appear to be more susceptible to the effects of alcohol on breathing. ${ }^{4,5}$ Furthermore, in persons with OSA, alcohol can increase the frequency and duration of apneas and the severity of associated hypoxemia. ${ }^{6-10}$

The effects of alcohol on breathing during sleep suggest that sleep-disordered breathing (SDB) may be an important contributor to sleep complaints and sleep disruption in alcoholics. Previous studies showed that apnea was common, especially in older male alcoholics. For example, Tan et al. ${ }^{11}$ found that abstinent male alcoholics had increased numbers of central and obstructive apneas and hypopneas, compared with controls, whereas Mamdani and coworkers ${ }^{12}$ found that $31 \%$ of 80 abstinent alcoholic men had an apnea-hypopnea index (AHI) $>5$. In an earlier report on a cohort of 75 abstinent alcoholics, our group found SDB $(\mathrm{AHI}>10)$ in $25 \%$ of males between ages 40 to 59 , and $75 \%$ of males over age $60 .{ }^{13}$ Nocturnal hypoxemia, observed in some studies of alcoholics, may be due in part to smoking; but, in one study, severity of hypoxemia correlated better with duration of alcohol use than with smoking history or age. ${ }^{14,15}$ Thus, sleep apnea probably contributed to nocturnal hypoxemia in these subjects, although full polysomnography was not performed.

The exacerbation of sleep apnea by alcohol consumed within a few hours of sleep onset, ${ }^{4,6,7,9,10}$ and the association of sleep apnea with cardiovascular morbidity and mortality ${ }^{16-19}$ suggests that the occurrence of sleep apnea in 
alcoholics and other heavy alcohol users is an important clinical problem.

Excessive daytime sleepiness, loud snoring, and periods of apnea witnessed by the bed partner are the usual presenting symptoms of OSA. Reliable demographic predictors include high body mass index (BMI), older age, and male gender. ${ }^{20}$ The prevalence of OSA is $\sim 2 \%$ in adult women and $4 \%$ in adult men. ${ }^{21}$

Clinical assessment of symptoms suggestive of OSA includes evaluation of clinical features, responses to one or more sleep related questionnaires, and polysomnography. Schafer et al. ${ }^{22}$ reported a method for screening symptomatic patients using home-based monitoring, which yielded high sensitivity ( $94 \%$ ), but low specificity ( $41 \%$ ), when used alone. Accuracy improved (specificity of $92 \%$ ) when home monitoring was used in combination with clinical features and questionnaire responses. Pouliot et al. ${ }^{23}$ assessed use of the Epworth Sleepiness Scale (ESS), a measure of excessive daytime sleepiness, alone and in combination with clinical data (BMI and history of observed apneas) to identify patients with suspected OSA who were likely to have less severe apnea [apnea index $(\mathrm{AI})<20$ ]. The ESS score alone had poor predictive value, with $40 \%$ of the patients identified as lower risk $(\mathrm{AI}<20)$ being misclassified (AI $>20$ on polysomnography). ESS combined with BMI improved the accuracy, with only $6 \%$ falsely classified as lower risk; but, the percentage of patients misclassified as higher risk was increased. Douglass et al. ${ }^{24}$ reported adequate validation, and a test-retest reliability of 0.84 for the Apnea Scale of the Sleep Disorders Questionnaire (SDQ) used in the study presented herein. However, no independent studies on use of the SDQ Apnea Scale for identification of suspected OSA have been published. Simplified diagnostic procedures based on questionnaire responses and clinical presentation may eventually allow a broader range of patients to be evaluated for OSA. Currently, however, simplified diagnostic procedures have not proven to be valid or reliable. Definitive diagnosis of OSA still requires full polysomnography.

We report herein an extension of our previous work, ${ }^{13}$ which includes studies of an additional 113 abstinent alcoholics undergoing treatment for alcoholism (total sample $=$ 188 ) and a comparison group of 87 normal subjects.

\section{METHODS}

Subjects were recruited from alcohol treatment programs at the University of Michigan Hospitals, the Ann Arbor Veterans Administration Medical Center, and the Chelsea Arbor Treatment Center. All subjects had alcoholism diagnosed by clinical evaluation and Diagnostic Interview Schedule $^{25}$ and were undergoing treatment for alcoholism. Mean years of heavy drinking was $11.8 \pm 9.3$ (mean \pm SD). Potential subjects were excluded if they had a history of major depressive illness, or if they had advanced cirrhosis with jaundice, a portocaval shunt, or a prothrombin time $>19 \mathrm{sec}$. Other exclusionary criteria included dementia (alcoholic or otherwise), aphasia, major stroke, and schizophrenia; current use of medications known to affect sleep, including centrally acting antihypertensive medications, antihistamines, sedatives, hypnotics, stimulants, or other psy- chotropic medications. All subjects had been free of alcohol for at least 2 weeks at the time of sleep recordings. A total of 189 subjects were recruited; however, one woman subject slept for only $55 \mathrm{~min}$ during the recorded night and was excluded from the analysis. The range of total sleep time for the remaining subjects was 153 to 406 min (mean $=307 \pm$ $52 \mathrm{~min}$ ). The study sample therefore consisted of 188 adult alcoholics ( 160 men, 28 women), with an age range of 22 to 76 years.

One hundred and seventy-eight of the 188 subjects also completed the $S D Q,{ }^{24}$ a standardized instrument used in the assessment of persons with suspected sleep disorders in which possible answers are "never," "rarely," "sometimes," "usually," and "always." The following items were analyzed-Q3: I have trouble getting to sleep at night; Q4: I wake up often during the night; Q14: My night sleep is restless and disturbed; Q15: At night, my sleep disturbs my bed partner's sleep; Q20: I snore in my sleep; Q21: I am told I snore loudly and bother others; Q22: I am told I stop breathing ("hold my breath") in sleep; Q23: I awake suddenly gasping for breath, unable to breathe; and Q55: Now, I am very sleepy during the day, and I struggle to stay awake.

Subjects who entered the study before March 1, 1993 completed multiple nights of polysomnography, whereas subjects studied after that date completed only one night. To ensure that the sample was homogeneous with regard to potential first night effects, only data from the first night of polysomnography were used for the analyses presented herein. After giving informed consent, subjects were studied using standard polysomnographic techniques that recorded the following measures: electroencephalogram (C3, C4, O1, O2 by International 10-20 system), chin electromyogram, electrooculogram, electrocardiogram, respiratory effort (mercury strain gauges or piezoelectric belts over the chest and abdomen), airflow at the nose and mouth (thermistors), and bilateral anterior tibialis electromyogram with surface electrodes. Continuous monitoring was performed by experienced polysomnographic technologists. Oxyhemoglobin saturation $\left(\mathrm{SaO}_{2}\right)$ was monitored by pulse oximetry (Ohmeda Corporation, Liberty Corner, NJ).

All studies were recorded either on paper at $10 \mathrm{~mm} / \mathrm{sec}$ paper speed using polygraphs (Grass Instruments, Quincy, MA), or on paperless computerized data acquisition systems (Oxford Instruments, Largo, FL; Telefactor Corporation, Conshohocken, PA). No automated scoring was performed; all recordings were scored manually for sleep stages by experienced polysomnographic technologists using standard techniques. ${ }^{26}$ Sleep latency was defined in this study as the time from the start of the recording (lights out) to the onset of at least 10 continuous min of stage 2 , 3,4 , or rapid eye movement (REM) sleep that was interrupted by no more than $2 \mathrm{~min}$ of stage 1 or $1 \mathrm{~min}$ of stage $1+1 \mathrm{~min}$ of wakefulness. The REM sleep latency was defined as the time between sleep onset, as defined herein, and the first REM period, minus any intermittent wakefulness during that interval.

Apneas were defined as absence of airflow for $10 \mathrm{sec}$ or more. Hypopneas were defined as a decrease in respiratory effort with a parallel reduction in nasal-oral airflow lasting $10 \mathrm{sec}$ or longer associated with a $3 \%$ or greater drop in oxygen saturation or with an arousal. An AHI was calculated as the number of apneas plus hypopneas per hour of sleep. An AI was computed as the number of apneas per hour of sleep. Periodic leg movements were scored according to the criteria of Coleman. ${ }^{27}$ A periodic leg movement index (PLMI) was calculated as the number of periodic leg movements occurring during sleep divided by the number of hours of sleep.

We also completed a secondary analysis that compared a subsample of the alcoholics to a group of 87 healthy nonalcoholic subjects who had been recruited from the community for a study of the effects of low-dose alcohol on sleep. The healthy volunteers were screened for probable existence of sleep disorders and were excluded from the study if they scored above the 70th percentile on any of the four scales of the SDQ. The scales have been validated for assessment of narcolepsy, sleep apnea, periodic limb movements, and psychiatric causes of sleep disturbance. ${ }^{24}$ To make the comparison groups as similar as possible, the alcoholic subsample also included only subjects who scored below the 70 th percentile on all four scales of the SDQ $(n=139)$. Like the alcoholic sample, the 
halthy volunteers were also screcened for current and past medical and psychiatric conditions through a comprehensive interview that included the Diagnostic Interview Schedule and were excluded if they had a history or current stai ss of significant psychiatric or medical illness, including major depression, bipolar disorder, dysthymia, anxiety disorder, psychosis, posttraumatic stress disorder, personality disorder, drug or alcohol dependence or abusc, significant heart discase, scizure disorder, liver disease, gastrointestinal disease, loss of consciousness, stroke, or transient ischemic attack. They were also excluded if they took medications known to affect sleep, including centrally acting antihypertensive medications, antihistamines, sedatives, hypnotics, stimulants, or other psychotropic medications. Participants were required to have regular night time sleep habits and were excluded if they worked rotating shifts or night shifts. A total of 87 normal subjects met these criteria and underwent one night of sleep laboratory adaptation, followed by one night of sleep laboratory baseline recording, followed by one or more nights of alcohol consumption before sleep. Only the night of baseline recording was used for comparison with the subsct of alcoholic subjects.

Statistical analysis was performcd using SPSS for Windows (SPSS, Inc., Chicago, IL). We used the AHI as the primary measure of apnea severity and selected an AHI of 10 as a cutpoint for defining the presence of sleep apnea. We also assessed another commonly used cutpoint: an AHI of 5 .

\section{RESULTS}

\section{$S D B$}

In the sample of 188 alcoholics, a multiple regression analysis of age and sex on normalized $\mathrm{AHI}$, while controlling for BMI, was significant $\left(R^{2}=0.313, F=27.9, p<\right.$ $0.001)$ and revealed main effects for all three predictors: age $(t=6.0, p<0.001), \operatorname{sex}(t=0.55, p=0.007)$, and BMI $(t=4.8, p<0.001)$.

Twenty-four alcoholic subjects (12.8\%) had an AHI $\geq$ 10 , and $44(23.4 \%)$ had an $\mathrm{AHI} \geq 5$. Of the 160 alcoholic men, $24(15.0 \%)$ had an AHI of $\geq 10$ events/hr and 43 (26.9\%) had an $\mathrm{AHI} \geq 5$. Of the 28 women, none had an $A H I \geq 10$, and 1 had an $A H I \geq 5$. The gender differences in prevalence of SDB were significant for both cutpoints ( $p<0.001$ by Fisher's exact test). In most subjects with SDB, the respiratory events were predominantly obstructive. On average, SDB was of moderate severity among the subjects with an $\mathrm{AHI} \geq 10$, with a mean $\mathrm{AHI}$ of 29.2 and a mean minimum $\mathrm{SaO}_{2}$ of $81.3 \%$.

The proportions of alcoholics with SDB (AHI $\geq 10$ ) for age groups 20 to 29 years $(n=31), 30$ to 39 years $(n=60)$, 40 to 49 years $(n=68), 50$ to 59 years $(n=15)$, and age 60 or over $(n=14)$ are shown in Fig. 1. Of those over age 40 years, $23.5 \%$ had an $\mathrm{AHI} \geq 10$, compared with $3.9 \%$ of those age 40 and under $(p<0.001)$. Using an $\mathrm{AHI} \geq 5$ as the cutpoint, the increase in the proportion of subjects over age 40 also was highly significant $(10.7 \%$ for younger alcoholics and $38.8 \%$ for older alcoholics; $p<0.001$ ).

We compared polysomnographic features of alcoholic subjects with and without SDB using the multivariate General Linear Model to control for multiple comparisons; the results are shown in Table 1 . Statistically significant differences $(p<0.05)$ included: (1) subjects with $\mathrm{AHI} \geq 10$ had more stage 1 sleep, less stage 2 sleep, and more PLMs; (2) the association with PLMs was age-dependent: the propor-

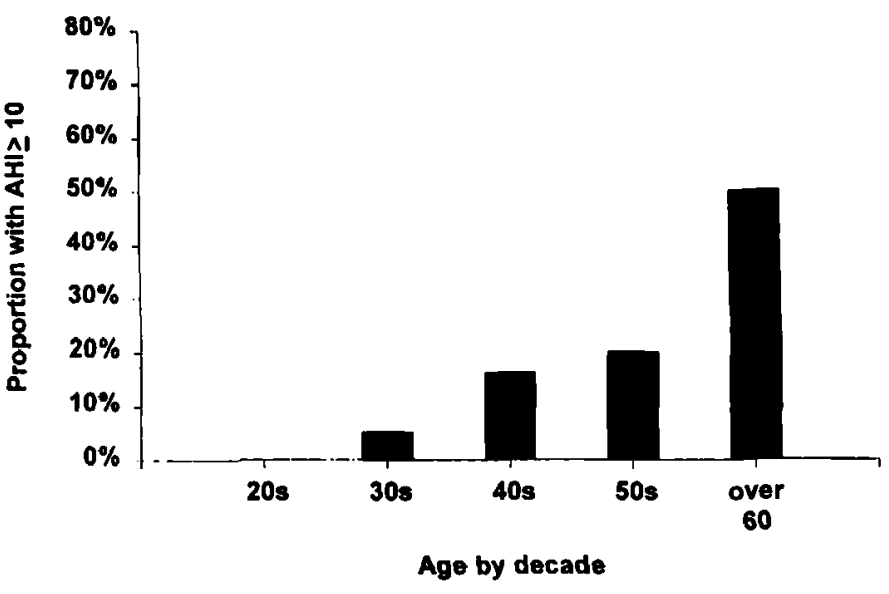

Fig. 1. Proportions of alcoholics with $S D B$, defined by an $A H I I 10$, by decade.

tion of alcoholics with PLMI $\geq 10$ was $11.3 \%$ overall, $5.8 \%$ in those age $\leq 40$, and $16.5 \%$ in those age $>40(p=0.018$ for those $\leq 40$ vs. those $>40$ ); and (3) subjects with $\mathrm{AHI} \geq$ 10 had significantly lower time asleep, longer latency to continuous sleep, lower sleep efficiency, and shorter REM sleep latency. All statistically significant differences remained significant when men only were analyzed.

Subjective assessments of sleep also revealed differences between alcoholics with SDB, compared with those without. Those with $\mathrm{AHI} \geq 10$ were more likely to report that they "never" had trouble getting to sleep at night than those with $\mathrm{AHI}<10$ (21.7\% vs. $6.5 \% ; p<0.001)$ and that they usually or always felt very sleepy or struggled to stay awake during the day $(13.0 \%$ vs. $3.2 \%$; $p<0.001)$. With $\mathrm{AHI}$ as a continuous variable and age as a covariate, the following questionnaire items differed between alcoholics with $\mathrm{AHI} \geq 10$ and those with $\mathrm{AHI}<10$, with apneic alcoholics reporting greater frequencies of the symptomsQ15: At night, my sleep disturbs my bed partner's sleep ( $F=5.1 ; p=0.001$ ); Q22: I am told I stop breathing ("hold my breath") in sleep ( $F=5.6 ; p<0.001)$; Q55: Now, I am very sleepy during the day, and I struggle to stay awake $(F=12.6 ; p<0.001)$.

To determine whether responses to these SDQ questions (Q15, Q22, and Q55) would help predict the presence of SDB in alcoholics, a logistic regression was run with age, $\mathrm{BMI}$, and the $3 \mathrm{SDQ}$ questions as predictor variables and AHI $>10$ (yes or no) as the response variable. Using only age and $\mathrm{BMI}$ as predictors, the model correctly classified $97 \%$ of subjects without SDB (AHI $<10$ ), but only $22 \%$ of subjects with SDB (AHI > 10). Adding the SDQ questions increased the number of correctly classified subjects without SDB to $99 \%$, and the number of correctly classified with SDB to $43 \%\left(R^{2}=0.5, p<0.001\right)$.

\section{Comparison with Normal Subjects}

We compared polysomnographic and questionnaire data from the alcoholics to a group of normal subjects recruited 
Table 1. Sleep in 188 Alcoholics With and Without SDB (Mean \pm SD)

\begin{tabular}{|c|c|c|c|c|}
\hline & All subjects & $\begin{array}{l}\text { SDB absent } \\
(\mathrm{AHI}<10)\end{array}$ & $\begin{array}{l}\text { SDB present } \\
(A H I \geq 10)\end{array}$ & $\underset{\text { MLM }}{p} \stackrel{p}{\text { Multivariate }}$ \\
\hline No. of subjects & 188 & 164 & 24 & \\
\hline Age & $40.8 \pm 11.1$ & $39.3 \pm 10.1$ & $51.3 \pm 12.4$ & $<0.001$ \\
\hline Gender ratio & $160 \mathrm{M} / 28 \mathrm{~F}$ & $136 \mathrm{M} / 28 \mathrm{~F}$ & $24 \mathrm{M}$ & 0.051 \\
\hline $\mathrm{BMI}$ & $25.8 \pm 4.5$ & $25.3 \pm 4.1$ & $29.0 \pm 6.3$ & $<0.001$ \\
\hline$\%$ Smokers & 85 & 84 & 87 & NS \\
\hline Smoking (pack-years) & $22.9 \pm 19.2$ & $21.6 \pm 18.4$ & $31.5 \pm 22.6$ & 0.010 \\
\hline Years of heavy drinking & $11.8 \pm 9.3$ & $11.5 \pm 8.7$ & $13.8 \pm 12.8$ & NS \\
\hline Recording time (min) & $386.8 \pm 32.8$ & $387.6 \pm 32.6$ & $381.3 \pm 34.5$ & NS \\
\hline Time awake (min) & $79.1 \pm 46.9$ & $74.2 \pm 45.0$ & $112.6 \pm 46.7$ & $<0.001$ \\
\hline Time asleep (min) & $307.7 \pm 50.8$ & $313.5 \pm 48.0$ & $268.7 \pm 52.8$ & $<0.001$ \\
\hline Sleep latency (min) & $37.5 \pm 34.3$ & $34.2 \pm 32.6$ & $60.2 \pm 37.6$ & $<0.001$ \\
\hline Latency to REM sleep (min) & $71.2 \pm 51.5$ & $75.2 \pm 49.9$ & $44.0 \pm 55.3$ & 0.004 \\
\hline Sleep efficiency $(\%)$ & $79.6 \pm 11.8$ & $81.0 \pm 11.2$ & $70.4 \pm 11.8$ & $<0.001$ \\
\hline Stage 1 sleep (\%) & $24.1 \pm 13.7$ & $21.0 \pm 9.56$ & $45.4 \pm 18.1$ & $<0.001$ \\
\hline Stage 2 sleep $(\%)$ & $47.2 \pm 12.4$ & $49.7 \pm 10.1$ & $30.7 \pm 13.6$ & $<0.001$ \\
\hline Stage REM sleep (\%) & $20.2 \pm 6.6$ & $20.4 \pm 6.7$ & $18.8 \pm 6.3$ & NS \\
\hline Stage 3-4 sleep (\%) & $8.5 \pm 9.3$ & $9.0 \pm 9.3$ & $5.1 \pm 8.0$ & 0.061 \\
\hline AHI & $5.1 \pm 13.1$ & $1.5 \pm 2.6$ & $29.2 \pm 25.7$ & $<0.001$ \\
\hline Baseline nocturnal $\mathrm{SaO}_{2}(\%)$ & $95.7 \pm 1.7$ & $95.8 \pm 1.7$ & $95.0 \pm 1.7$ & 0.014 \\
\hline Minimum nocturnal $\mathrm{SaO}_{2}(\%)$ & $89.3 \pm 6$ & $90.5 \pm 4.2$ & $81.3 \pm 9.6$ & $<0.001$ \\
\hline$\%$ with PLM index $>10$ & 11 & 8 & 29 & $<0.001$ \\
\hline
\end{tabular}

GLM, General Linear Model; M, male; F, female; NS, not significant.

from the community as described in "Methods." Because the responses to the SDQ were used as selection criteria for the normal subjects (see "Methods"), we compared the 87 normal subjects ( $57 \mathrm{men}, 30$ women) to only those alcoholics who also did not score above the 70th percentile on any of the SDQ scales. Of the 188 alcoholics, 139 met these criteria.

The SDQ Apnea Scale score is based on the responses to 12 items that relate to snoring, gasping, witnessed apneas, nocturnal sweating, high blood pressure, nasal obstruction, body weight, BMI, number of smoking years, and age. ${ }^{24}$ It thus includes the major clinical predictors of OSA. ${ }^{28,29}$ Because the SDQ Scale for sleep apnea was one of the selection criteria, the exclusion of those persons scoring above the 70th percentile on the Apnea Scale means that the normal subjects and the subgroup of alcoholics who were compared with normal subjects did not have strong symptoms or clinical predictors of obstructive sleep apnea syndrome. Despite the lack of self-reported symptoms, $12 \%$ of the alcoholics in the subsample (17 of 139 cases) had clinically significant SDB on polysomnography, with AHI $>10$. Similarly, $12 \%$ of controls ( 10 of 82 subjects for whom SDQ scores were available) had clinically significant SDB on polysomnography. Because both groups are comprised solely of subjects with normal apnea scale scores, sensitivity and specificity of the scale cannot be computed from our data.

In these groups with relatively low likelihood of OSA syndrome, we also found that mild SDB (AHI $\geq 5$ ) was more common in the alcoholic subjects than in the controls in age-matched subgroups. For example, among subjects over age 55 , the proportion with $\mathrm{AHI} \geq 5$ was $67 \%$ for the alcoholics and $31 \%$ for the controls $(p=0.026$ by Fisher's exact test). Among subjects over the age of 40 , the proportion with $\mathrm{AHI} \geq 5$ was $41 \%$ for the alcoholics and $23 \%$ for the controls $(p=0.035)$. Among subjects $<$ age 55 , the proportion with $\mathrm{AHI} \geq 5$ was $19 \%$ for the alcoholics and $7 \%$ for the controls $(p=0.029)$, whereas among subjects $<$ age 40 , the proportion with AHI $\geq 5$ was $11 \%$ for the alcoholics and $0 \%$ for the controls $(p=0.046)$. Thus, among alcoholics and normal subjects matched for the relative absence of sleep-related symptoms, alcoholics of all ages were more likely to have mild SDB. In addition, nocturnal hypoxemia was more pronounced in the alcoholic group, with a lower baseline nocturnal $\mathrm{SaO}_{2}(p<$ $0.001)$ and a lower minimum $\mathrm{SaO}_{2}(p<0.001)$ (Table 2). Furthermore, we found a significant interaction between group (alcoholics vs. nonalcoholics) and age for the AHI $(F=8.67 ; p<0.001)$.

We also assessed sleep architecture in the normal subjects and the group of 139 alcoholics meeting the SDQ criteria (Table 2). In this comparison, alcoholics had less sleep time $(p<0.001)$, lower sleep efficiency $(p=0.009)$, more stage 1 sleep $(p=0.009)$, and less delta sleep ( $p=$ 0.007 ). Differences in sleep architecture were more pronounced in younger subjects than in older subjects. Among subjects age 40 or less, alcoholics had less sleep ( $p<$ $0.001)$, more time awake $(p=0.003)$, longer sleep latency $(p=0.044)$, lower sleep efficiency $(p=0.001)$, more stage 1 sleep $(p=0.001)$, and less delta sleep $(p=0.029)$. On the other hand, the only significant difference among subjects over age 40 was a reduction in sleep time among alcoholics $(p=0.016)$.

\section{DISCUSSION}

We found SDB, primarily obstructive, in a substantial proportion of alcoholics, with a strong association with age. Alcoholics with SDB were more likely to be men and had more sleep disruption, more complaints of daytime sleepiness, and 
Table 2. Alcoholics and Control Subjects with Relative Absence of Sleep-Related Symptoms by SDQ

\begin{tabular}{|c|c|c|c|}
\hline & Alcoholics & Normal subjects & $\begin{array}{c}p \\
\text { Multivariate } \\
\text { GLM }\end{array}$ \\
\hline No. of subjects & 139 & 87 & \\
\hline Age & $40.7 \pm 11.4$ & $47.1 \pm 14.6$ & $<0.001$ \\
\hline Sex ratio & $118 \mathrm{M} / 21 \mathrm{~F}$ & $57 \mathrm{M} / 30 \mathrm{~F}$ & $<0.001$ \\
\hline BMI & $25.6 \pm 4.2$ & $25.3 \pm 4.1$ & NS \\
\hline$\%$ Smokers & $83 \%$ & $2.3 \%$ & $<0.001$ \\
\hline Smoking (pack-years) & $21.2 \pm 18.8$ & $0.3 \pm 2.1$ & $<0.001$ \\
\hline Years of heavy drinking & $11.7 \pm 9.7$ & 0 & $<0.001$ \\
\hline Recording time (min) & $386.9 \pm 33.2$ & $408.7 \pm 29.3$ & $<0.001$ \\
\hline Time awake (min) & $77.2 \pm 46.5$ & $65.3 \pm 52.6$ & $<0.001$ \\
\hline Time asleep (min) & $309.7 \pm 50.8$ & $343.4 \pm 55.9$ & $<0.001$ \\
\hline Sleep latency (min) & $35.6 \pm 33.2$ & $28.2 \pm 35.2$ & NS \\
\hline Latency to REM sleep (min) & $76.1 \pm 54.0$ & $72.9 \pm 43.4$ & NS \\
\hline Sleep efficiency $(\%)$ & $80.1 \pm 11.7$ & $84.1 \pm 12.7$ & 0.007 \\
\hline Stage 1 sleep (\%) & $24.1 \pm 14.1$ & $18.9 \pm 15.1$ & 0.009 \\
\hline Stage 2 sleep (\%) & $47.9 \pm 12.6$ & $50.4 \pm 12.8$ & NS \\
\hline Stage REM sleep (\%) & $20.1 \pm 6.5$ & $19.3 \pm 6.1$ & NS \\
\hline Stage 3-4 sleep (\%) & $8.0 \pm 8.8$ & $11.4 \pm 10.1$ & 0.007 \\
\hline $\mathrm{AHI}$ & $4.6 \pm 11.5$ & $5.1 \pm 18.5$ & NS \\
\hline Baseline $\mathrm{SaO}_{2}(\%)$ & $95.7 \pm 1.7$ & $97.4 \pm 1.4$ & $<0.001$ \\
\hline Minimum $\mathrm{SaO}_{2}(\%)$ & $89.5 \pm 5.6$ & $94.6 \pm 6.8$ & $<0.001$ \\
\hline$\%$ with PLM index $>10$ & $10.6 \%$ & $8 \%$ & NS \\
\hline
\end{tabular}

GLM, General Linear Model; M, male; F, female; NS, not significant.

more hypoxemia than alcoholics without SDB. The severity of SDB, as defined by the AHI, was a function of age and BMI. When these two factors were controlled for, severity of SDB was not significantly affected by smoking history or by the duration of heavy drinking. In a comparison of alcoholics and normal subjects who were matched for a relative absence of sleep complaints, alcoholics of all age groups were more likely to have mild SDB. They also had more nocturnal hypoxemia and greater degrees of sleep disruption. These findings indicate that: (1) SDB is common among alcoholics, especially older alcoholics; (2) SDB in alcoholics is associated with significant effects on nocturnal oxygenation; and (3) SDB is a substantial contributor to daytime sleep-related symptoms in alcoholics.

As described in "Methods," some of the alcoholics in our sample had multiple nights of polysomnography and some had only one. To ensure that data for the full sample were homogeneous, only the first night measurements for all subjects were analyzed. This raises the question of whether one night is sufficient for assessment of SDB. Characteristics of sleep in a sleep laboratory differ on the first night of sleep when compared with subsequent nights. The "firstnight effects" include increased sleep latency, increased REM sleep latency, and reduced amounts of REM sleep. However, the first-night effects on breathing appear to be much less. Dickel and Mosko ${ }^{30}$ found no first-night effect on the frequency of respiratory events in 100 seniors evaluated for sleep apnea and periodic leg movements. Bliwise and associates ${ }^{31}$ found that measures of disordered breathing were fairly stable across two nights, although there was an mild increase in some subjects on the second night. Thus, whereas night-to-night variability in severity of SDB occurs in individuals, current evidence suggests that one night of study is sufficient to characterize SDB in groups of research subjects.
The increase in SDB with age confirms our earlier findings, ${ }^{13}$ and the association of polysomnographically confirmed SDB with symptoms of poor sleep and daytime sleepiness suggests that our data are clinically relevant. That SDB increases with age in alcoholics is not surprising, because its prevalence increases with age in the general population. ${ }^{32}$ However, whereas SDB is common among the elderly, a wide range of prevalence rates have been reported (see Bliwise ${ }^{32}$ for review). Differences in reported prevalence rates probably reflect differences in recruitment methods and differences in definitions of SDB.

Because our group of normal subjects was not representative of the general population, our data do not allow us to determine whether sleep apnea is more prevalent among alcoholics than among the general population for various age groups. However, our results do suggest that the prevalence of SDB is not markedly increased in middle-aged alcoholics, compared with the general population. For example, the prevalence of SDB (defined as AHI $\geq 10$ ) in alcoholic men between the ages of 40 and 60 in this study ( $18 \%$ for ages 40 to 49 and $25 \%$ for ages 50 to 59 ) is only modestly higher than the prevalence of $14 \%$ and $18 \%$ for these age groups reported by Young et al. ${ }^{21}$ in a study of men from Wisconsin. In our study, 1 of 28 women alcoholics $(3.6 \%)$ had SDB, a prevalence similar to the $5 \%$ for middle-aged women in the study by Young et al.

Daytime sleepiness, a major complaint in most persons with SDB, is caused at least in part by sleep fragmentation associated with resumption of breathing. In alcoholics with SDB, evening alcohol use is likely to increase the frequency and severity of obstructive apneas, leading to greater sleep disruption and more pronounced daytime effects. Furthermore, sleepiness caused by sleep disruption or other factors associated with SDB may add to sedative effects of alcohol 
to produce greater impairments of daytime alertness and cognitive function.

The greater severity of hypoxemia in association with SDB in alcoholic subjects, compared with nonalcoholic subjects, may have important clinical implications. The high rate of cigarette smoking in the alcoholic group, combined with SDB, probably accounts for the more severe hypoxemia. Our studies were performed in abstinent alcoholics; it is highly likely that hypoxemia is more severe in actively drinking alcoholics, because alcohol use tends to increase apnea duration and increase the severity of associated hypoxemia.

In addition to hypoxemia, obstructive apneas are often accompanied by reductions of cardiac output due to right to left shifts of the cardiac interventricular septum. Hypoxemia and acidosis may lead to increased pulmonary and systemic arterial blood pressure, despite the fall in cardiac output, whereas increased vagal tone and hypoxemia contribute to cardiac arrhythmias. Increased sympathetic nervous system activity during the arousals that accompany the end of apneas contributes to increased blood pressure and to the potential for dangerous ventricular tachyarrhythmias. SDB may contribute to daytime systemic hypertension in some patients as a result of hypoxemia or altered sympathetic activity. ${ }^{28}$ Because alcohol also may lead to increased ventricular ectopy, ${ }^{33,34}$ alcoholics with SDB who are actively drinking are likely to be at increased risk for suspected cardiovascular complications of SDB, including stroke, myocardial infarction, and sudden death. ${ }^{16-19,35-39}$ Thus, SDB, when combined with existing cardiovascular risk factors and alcohol use, may be a significant factor in the increased risk of stroke and mortality that occurs in alcohol users. ${ }^{40,41}$

Our findings suggest that SDB is common in alcoholics and that it may contribute to poor treatment outcome and increased risk of stroke, myocardial infarction, and sudden death in these patients. Impairments in daytime functioning commonly associated with SDB, including decreased alertness and impaired cognitive function, may affect alcohol treatment response. In addition, alcoholics who are actively drinking are likely to experience a higher frequency of obstructive apneas and more severe hypoxemia, which can lead to greater sleep disruption and more pronounced daytime effects. Clinical evaluation of sleep-related complaints and treatment of SDB may help decrease the incidence of cardiovascular morbidity and mortality, and may help improve the response to alcohol treatment.

\section{ACKNOWLEDGMENT}

We thank Dr. Elizabeth Hill for statistical consultation.

\section{REFERENCES}

1. Robinson RW, White DP, Zwillich CW: Moderate alcohol ingestion increases upper airway resistance in normal subjects. Am Rev Respir Dis 132:1238-1241, 1985

2. Mitler MM, Dawson A, Henriksen SJ, Sobers M, Bloom FE: Bed- time ethanol increases resistance of upper airways and produces sleep apneas in asymptomatic snorers. Alcohol Clin Exp Res 12:801-805, 1988

3. Dawson A, Lehr P, Bigby BG, Mitler MM: Effect of bedtime ethanol on total inspiratory resistance and respiratory drive in normal nonsnoring men. Alcohol Clin Exp Res 17:256-262, 1993

4. Block AJ. Hellard DW, Slayton PC: Effect of alcohol ingestion on breathing and oxygenation during sleep. Analysis of the influence of age and scx. Am J Med 80:595-600, 1986

5. Block AJ: Alcohol ingestion does not cause sleep-disordered breathing in premenopausal women. Alcohol Clin Exp Res 8:397-398, 1984

6. Taasen VC, Block AJ, Boysen PG, Wynne JW, White C, Lindsey S: Alcohol increases sleep apnea and oxygen desaturation in asymptomatic men. Am J Med 71:240-245, 1981

7. Issa FG, Sullivan CE: Alcohol, snoring and sleep apnoea. J Ncurol Neurosurg Psychiatr 45:353-359, 1982

8. Collop NA: Medroxyprogesterone acetate and ethanol-induced exacerbation of obstructive sleep apnea. Chest 106:792-799, 1994

9. Scrima L, Hartman PG, Hiller FC: Effect of three alcohol doses on breathing during sleep in 30-49 year old nonobese snorers and nonsnorers. Alcohol Clin Exp Res 13:420-427, 1989

10. Scrima L, Broudy M, Nay KN, Cohn MA: Increased severity of obstructive sleep apnea after bedtime alcohol ingestion: Diagnostic potential and proposed mechanism of action. Slcep 5:318-328, 1982

11. Tan ET, Lambic DG, Johnson RH, Robinson BJ, Whiteside EA: Sleep apnoca in alcoholic patients after withdrawal. Clin Sci 69:655-661. 1985

12. Mamdani M, Hollyfield R, Ravi SD, Dorus W, Borge GF: Prevalence of sleep apnca among abstinent chronic alcoholic men. Sleep Res 18:349, 1989

13. Aldrich MS, Shipley JE, Tandon R, Kroll PD, Brower KJ: Sleep disordered breathing in alcoholics: Association with age. Alcohol Clin Exp Res 17:1179-1183, 1993

14. Vitiello MV, Prinz PN, Personius JP, Nuccio MA, Ries RK, Koerker RM: History of chronic alcohol abuse is associated with increased nighttime hypoxcmia in older men. Alcohol Clin Exp Res 11:368-371, 1987

15. Vitiello MV, Prinz. PN, Personius JP, Nuccio MA, Koerker RM, Scurfield R: Nighttime hypoxemia is increased in abstaining chronic alcoholic men. Alcohol Clin Exp Res 14:38-41, 1990

16. Palomaki H: Snoring and the risk of ischemic brain infarction. Stroke 22:1021-1025, 1991

17. Hoffstein V, Chan CK, Slutsky AS: Sleep apnca and systemic hypertension: A causal association review. Am J Med 91:190-196, 1991

18. Rossner S, Legerstrand L, Persson HE, Sachs C: The sleep apnoea syndrome in obesity: Risk of sudden death. J Int Med 230:135-141, 1991

19. Partinen $M$, Guilleminault $C$ : Daytime sleepiness and vascular morbidity at seven-year follow-up in obstructive sleep apnea patients. Chest 97:27-32, 1990

20. Kripke DF, Ancoli-Israel S, Klauber MR, Wingard DL, Mason WJ, Mullancy DJ: Prevalence of sleep-disordered breathing in ages 40-64 ycars: A population-based survey. Slcep 20:65-76, 1997

21. Young T, Palta M, Dempsey J, Skatrud J, Weber S, Badr S: The occurrence of sleep disordered breathing among middle-aged adults. N Engl J Med 328:1230-1235, 1993

22. Schafer H, Ewig S, Hasper E, Luderitz B: Predictive diagnostic value of clinical assessment and nonlaboratory monitoring system recordings in patients with symptoms suggestive of obstructive sleep apnea syndrome. Respiration 64:194-199, 1997

23. Pouliot Z, Peters $M$, Neufeld $H$, Kryger $M H$ : Using self-reported questionnaire data to prioritize OSA patients for polysomnography. Sleep 20:232-236, 1997

24. Douglass AB, Bornstein R, Nino-Murcia G, Keenan S, Miles L, Zarcone VP Jr, Guilleminault C, Dement WC: The Slecp Disorders Qucstionnaire. I. Creation and multivariate structure of SDQ. Sleep $17: 160-167,1994$

25. Robins LN, Helzer JE, Ratcliff KS: National Institute of Mental 
Health Diagnostic Interview schedule. Its history, characteristics, and validity. Arch Gen Psychiatry 38:381-389, 1981

26. Rechtschaffen A, Kales A: A manual of standardized terminology, techniques, and scoring system for sleep stages of human subjects. Brain Information Service/Brain Research Institute, Los Angeles, 1968

27. Coleman RM: Periodic movements in sleep (nocturnal myoclonus) and restless legs syndrome, in Guilleminault $\mathrm{C}$ (ed): Sleeping and waking disorders: indications and techniques. Menlo Park, Addison-Wesley, 1982, pp 265-295

28. Olson LG, King MT, Hensley MJ, Saunders NA: A community study of snoring and sleep-disordered breathing. Symptoms. Am J Respir Crit Care Med 152:707-710, 1995

29. Flemons WW, Whitelaw WA, Brant R, Remmers JE: Likelihood ratios for a sleep apnea clinical prediction rule. Am J Respir Crit Care Med 150:1279-1285, 1994

30. Dickel MJ, Mosko SS: Morbidity cut-offs for sleep apnea and periodic leg movements in predicting subjective complaints in seniors. Sleep 13:155-166, 1990

31. Bliwise DL, Carey E, Dement WC: Nightly variation in sleeprelated respiratory disturbance in older adults. Exp Aging Res 9:77-81, 1983 1993
33. Dolly FR, Block AJ: Increased ventricular ectopy and sleep apnea following ethanol ingestion in COPD patients. Chest 83:469-472, 1983

34. Guilleminault C, Silvestri R, Mondini S, Coburn S: Aging and sleep apnea: Action of benzodiazepine, acetazolamide, alcohol, and sleep deprivation in a healthy elderly group. J Gerontol 39:655-661, 1984

35. Olson LG, King MT, Hensley MJ, Saunders NA: A community study of snoring and sleep-disordered breathing. Health outcomes. Am J Respir Crit Care Med 152:717-720, 1995

36. Hung J, Whitford EG, Parsons RW, Hillman DR: Association of sleep apnoea with myocardial infarction in men. Lancet 336:261-264, 1990

37. Seppala T, Partinen M, Penttila A, Aspholm R, Tiainen E, Kaukianen $A$ : Sudden death and sleeping history among Finnish men. J Intern Med 229:23-28, 1991

38. Koskenvuo M, Kaprio J, Telakivi T, Partinen M, Heikkila K, Sarna S: Snoring as a risk factor for ischeamic heart disease and stroke in men. Br Med J 294:16-19, 1987

39. Smirne S, Palazzi S, Zucconi M, Chierchia S, Ferini-Strambi L: Habitual snoring as a risk factor for acute vascular disease. Eur Respir $\mathrm{J}$ 6:1357-1361, 1993

40. Gill JS, Zezulka AV, Shipley MJ, Gill SK, Beevers DG: Stroke and alcohol consumption. N Engl J Med 315:1041-1046, 1986

41. Klatsky AL, Armstrong MA, Friedman GD: Alcohol and mortality. Ann Intern Med 117:646-654, 1992 